\title{
Less invasive quick replacement for octogenarians with type $A$ acute aortic dissection
}

\author{
Mitsumasa Hata, MD, PhD, Mitsunori Suzuki, CE, Akira Sezai, MD, Tetsuya Niino, MD, Satoshi Unosawa, MD, \\ Nobuyuki Furukawa, MD, and Kazutomo Minami, MD
}

From the Department of Cardiovascular Surgery, Nihon University School of Medicine, Tokyo, Japan.

Funded by the Department of Cardiovascular Surgery, Nihon University School of Medicine, Tokyo, Japan.

Received for publication Nov 20, 2007; revisions received Dec 25, 2007; accepted for publication Jan 8, 2008.

Address for reprints: Mitsumasa Hata, MD, Department of Cardiovascular Surgery, $\mathrm{Ni}$ hon University School of Medicine, 30-1 Ooyaguchi Kamimachi Itabashi-ku, Tokyo 173-8610, Japan (E-mail: mihata@med. mihon-u.ac.jp).

J Thorac Cardiovasc Surg 2008;136:489-93 0022-5223/\$34.00

Copyright $\odot 2008$ by The American Association for Thoracic Surgery

doi:10.1016/j.jtcvs.2008.01.007
Objective: We assessed the efficacy of our newly modified technique, namely, less invasive quick replacement with rapid rewarming, for octogenarians undergoing emergency surgery for type A acute aortic dissection.

Methods: Forty-two patients with acute aortic dissection, whose average age was 81.7 \pm 2.3 years, were divided into two groups: group I consisted of 25 patients undergoing surgery with deep hypothermic circulatory arrest and selective cerebral perfusion; group II consisted of 17 recent patients who underwent less invasive quick replacement. In the latter technique, during open distal anastomosis with a rectal temperature of $28^{\circ} \mathrm{C}$ without any cerebral perfusion, circulating blood in the cardiopulmonary bypass circuit was warmed to $40^{\circ} \mathrm{C}$ accompanied by warming of the patient's body by a heating mat. As soon as the distal anastomosis was completed, rapid rewarming was initiated by $40^{\circ} \mathrm{C}$ blood perfusion.

Results: The durations of cerebral protection (group I, 75.8 minutes, vs group II, 18.8 minutes), cardiopulmonary bypass (I, 201.2, vs II, 84.4 minutes), and overall operation (I, 425.6, vs II, 148.6 minutes) were significantly shorter in group II. In group I, 5 patients had complications of cerebral damage and 5 required re-exploration for bleeding, 7 had pneumonia, 6 required hemodialysis for renal failure, and the hospital mortality rate was $24 \%$ (6 patients). On the other hand, no such complications or mortality were observed in group II $(P<.0291)$. Postoperative hospital stay was significantly shorter for the patients in group II than in group I (13.2 days vs 33.7 days; $P<.0001)$.

Conclusion: Less invasive quick replacement is safe and effective. It should be a standard surgical technique for octogenarians with type A acute aortic dissection.

I n our aging society, the number of octogenarians with cerebrovascular or respiratory disorders undergoing emergency surgery for type A acute aortic dissection (AAD) has been steadily increasing, and this may negate the impact of the beneficial advances. Although elderly patients with AAD may survive because of advances in surgical techniques, anesthesia, and perioperative medical management, various complications such as renal and respiratory failure, stroke, depression, or becoming bedridden may occur associated with extensive surgical stress. ${ }^{1}$ It therefore remains controversial whether emergency surgery for octogenarians with AAD is justified. We have established a new procedure, namely, less invasive quick replacement (LIQR), to prevent complications associated with long durations of cerebral protection and cardiopulmonary bypass (CPB). The aim of this study was to assess the efficacy of LIQR for octogenarians undergoing emergency surgery for AAD.

\section{Patients and Methods}

Between July 1995 and June 2007, 269 patients with AAD were admitted to our institution. Sixty-seven $(24.9 \%)$ patients were octogenarians. Among them, 42 patients underwent emergency surgical treatment. Institutional review board approval was provided before publication of this article and reporting of the information. Twenty-seven $(64.3 \%)$ patients were female, and the average age was $81.7 \pm 2.3$ years, ranging from 80 to 90 years. Contrast computed tomography was performed for all patients as soon as they were referred to the hospital. Transthoracic 


\section{Abbreviations and Acronyms}

$\mathrm{AAD}=$ acute aortic dissection

$\mathrm{ACP}=$ antegrade cerebral perfusion

$\mathrm{CPB}=$ cardiopulmonary bypass

DHCA $=$ deep hypothermic circulatory arrest

GRF = gelatin-resorcine-formalin

LIQR = less invasive quick replacement

echocardiography was then performed to detect pericardial effusion and to assess aortic valve regurgitation and cardiac function. Contrast computed tomography revealed a thrombosed occlusion-type condition in $9(21.4 \%)$ patients. Twenty $(47.6 \%)$ patients were in a preshock state owing to cardiac tamponade. Seven (16.7\%) patients had moderate aortic valve regurgitation and 9 (21.4\%) had had a transient ischemic attack. We divided them into two groups: group I consisted of 25 patients undergoing standard emergency surgery with deep hypothermic circulatory arrest (DHCA) and antegrade selective cerebral perfusion (ACP) to protect the brain; group II consisted of 17 recent patients who underwent our newly developed method, LIQR. We compared the two groups in terms of in-hospital mortality and morbidity.

\section{Surgical Procedure for Group I}

CPB was implemented through femoral arterial cannulation. DHCA and ACP for three arch vessels were used for cerebral protection. Each patient was cooled to $20^{\circ} \mathrm{C}$ (rectal temperature). The ascending aorta and/or aortic arch were then opened longitudinally with the aid of DHCA. The three arch vessels were then mobilized and balloon catheters were inserted for ACP. The aortic segment containing the intimal tear was resected and gelatin-resorcine-formalin (GRF) glue was applied between the two dissected walls on both the distal and proximal stumps of the aorta and fixed for 10 minutes. Furthermore, the aortic walls were reinforced by securing Teflon felt strips inside and outside the aorta. Antegrade systemic circulation was established through a side branch of the Dacron prosthesis after completion of open distal anastomosis.

\section{Surgical Procedure for Group II (LIQR)}

Circulatory arrest was implemented at a rectal temperature of $28^{\circ} \mathrm{C}$ without any cerebral perfusion. GRF glue was also used, but the aortic walls were reinforced by Teflon felt only outside the aorta just after the GRF glue was applied. During open distal anastomosis, circulating blood in the CPB circuit was warmed to $40^{\circ} \mathrm{C}$ by a maximum level of heat exchanger (Figure 1) and the patient's body was also warmed with a hyperthermia-hypothermia system (MediTherm II; Gaymar Industries, Inc, Orchard Park, NY) except for the patient's head. As soon as the distal anastomosis was completed, the antegrade systemic circulation was established through a side branch of the Dacron prosthesis and rapid rewarming was initiated by perfusion with $40^{\circ} \mathrm{C}$ blood (Figure 2).

\section{Statistical Examination}

Results were expressed as the mean \pm standard deviation. Statistical calculations were conducted with StatView software (SAS Institute, Inc, Chicago, Ill). By use of parametric and nonparametric data,

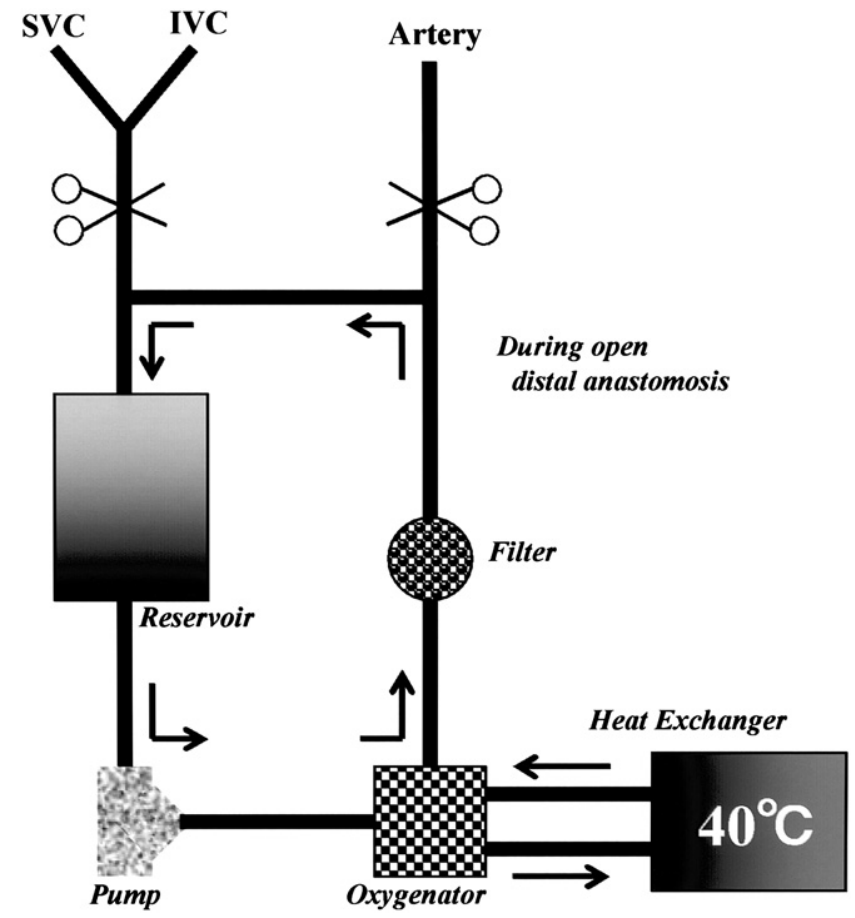

Figure 1. CPB circuit during open distal anastomosis. During open distal anastomosis, circulating blood in the CPB circuit was warmed to $40^{\circ} \mathrm{C}$. SVC, Superior vena cava; IVC, inferior vena cava.

statistically significant differences were determined by the Student $t$ test and Fisher exact test, respectively.

\section{Results}

There was no difference between the groups in terms of average age, sex, incidence of thrombosed occlusion, aortic valve regurgitation, cardiac tamponade, and cerebral infarction (Table 1). In group I, ascending and proximal hemiarch replacements were carried out in 15 and 9 patients, respectively. Total arch replacement with a 4-branch graft was required in 1 patient. An intimal tear was resected in 24 patients, but in 1 patient it was not identified. In group II, ascending and proximal hemiarch replacements were carried out in 8 and 9 patients, respectively. An intimal tear was resected in 15 patients, but in 2 patients, it was not identified. There was no difference in terms of such operative characteristics (Table 2). Rectal temperature was significantly higher in group II $\left(27.5^{\circ} \mathrm{C} \pm 0.5^{\circ} \mathrm{C}\right)$ than in group $\mathrm{I}\left(19.7^{\circ} \mathrm{C} \pm\right.$ $\left.0.9^{\circ} \mathrm{C} ; P<.0001\right)$. The durations of cerebral protection (group I, $75.8 \pm 17.9$ minutes, vs group II, $18.8 \pm 6.2$; $P<.0001)$, and CPB (I, $201.2 \pm 44.1$ minutes, vs II, 84.4 $\pm 14.3 ; P<.0001$ ), were significantly shorter in group II. The duration of overall operation in group II was $148.6 \pm$ 20.2 minutes, ranging from 118 to 175 minutes, which was significantly shorter than that in group I $(425.6 \pm 79.5$ minutes, $P<.0001$ ) (Table 3 ). There was no difference 


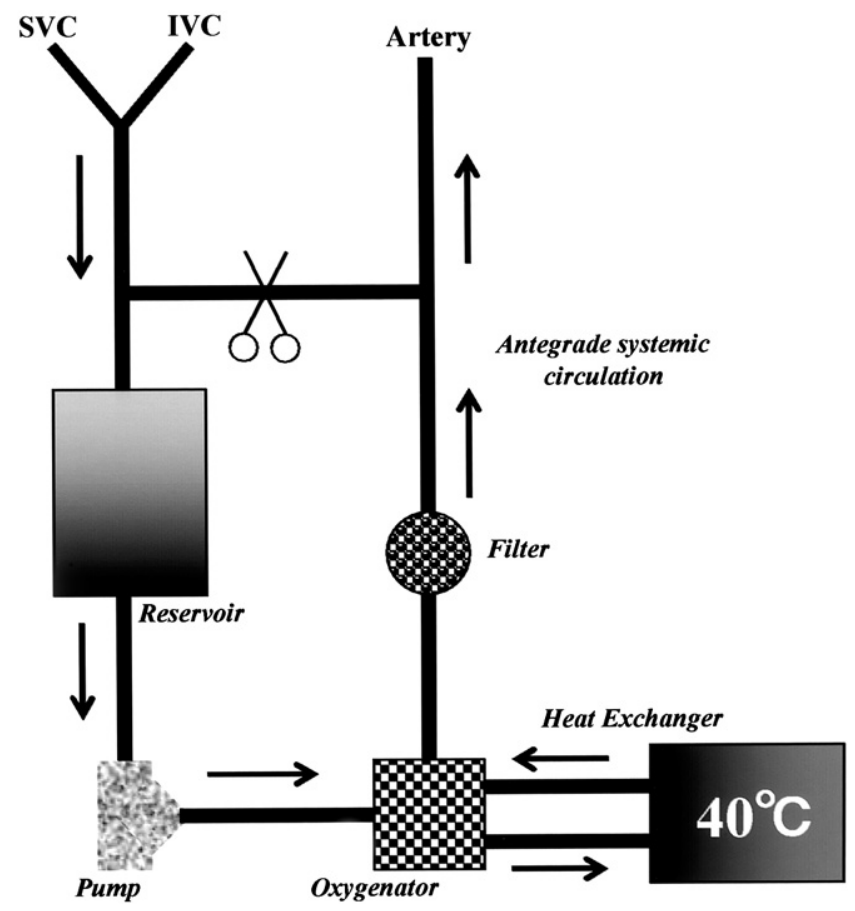

Figure 2. Rapid rewarming after open distal anastomosis. As soon as the distal anastomosis was completed, antegrade systemic circulation was established and rapid rewarming was initiated by perfusion with blood at $40^{\circ}$ C. SVC, Superior vena cava; IVC, inferior vena cava.

between the groups in terms of temporal neurologic dysfunction such as mild intellectual disturbance, confusion, disorientation, or memory disturbance (Table 4). In group I, 5 patients had complications of postoperative cerebral damage, 5 patients were taken back to the operating theater for bleeding, 6 patients required hemodialysis for postoperative renal failure, and 7 patients had pneumonia including 3 requiring a tracheostomy. The hospital mortality rate was $24 \%$ (6 patients). On the other hand, no such complications or mortality were observed in group II, except for 1 patient with a slight case of pneumonia (Table 4). The incidence of cerebral damage $(P=.0446)$, re-exploration for bleeding $(P=.0446)$, postoperative renal failure $(P=.0129)$, pneumonia $(P=$ $.0132)$, and mortality $(P=.0291)$ was significantly less in

TABLE 1. Preoperative morbidity

\begin{tabular}{lccc}
\hline & Group I & Group II & $\boldsymbol{P}$ value \\
\hline Age (y) & $81.8 \pm 2.4$ & \pm & NS \\
Sex (M/F) & $8 / 17$ & $7 / 10$ & NS \\
Occlusion type & $6(24 \%)$ & $3(17.6 \%)$ & NS \\
AR & $5(20 \%)$ & $2(11.8 \%)$ & NS \\
Tamponade & $12(48 \%)$ & $8(47.1 \%)$ & NS \\
Cerebral infarct & $1(4 \%)$ & 0 & NS \\
\hline
\end{tabular}

$A R$, Aortic regurgitation; NS, not significant.
TABLE 2. Operative characteristics

\begin{tabular}{lccc}
\hline & Group I & Group II & $\boldsymbol{P}$ value \\
\hline Ascending & $15(60 \%)$ & $8(47.1 \%)$ & NS \\
Hemiarch & $9(35 \%)$ & $9(52.9 \%)$ & NS \\
Total arch & $1(4 \%)$ & 0 & NS \\
Unknown entry & $1(4 \%)$ & $2(11.8 \%)$ & NS \\
\hline
\end{tabular}

group II than in group I. The postoperative hospital stay was also significantly shorter in group II (13.2 \pm 3.9 days $)$ than in group I ( $33.7 \pm 12.2$ days; $P<.0001$, Table 3$)$. In group I, although emergency aortic replacement was successfully completed, 5 patients became bedridden because of cerebral damage or severe depression after surgery, and 2 of those patients died of pneumonia or stroke 3 months after surgery in a care institution. On the other hand, all patients of group II are well at the time of writing, without any complications having been identified at the outpatient clinic.

\section{Discussion}

With the ever-increasing human lifespan, cardiovascular surgeons are faced with treating an increasing number of elderly patients. The efficacy of emergency surgical intervention for AAD is widely accepted, but its role in the treatment of octogenarians with AAD remains unclear. Surgical mortality and morbidity rates are especially high in elderly as compared with younger patients. ${ }^{2,3}$ Additionally, if a patient survives the operation but subsequently becomes bedridden, the family might complain bitterly about the situation and refuse payment. ${ }^{1}$ Therefore, controversy still exists as to whether surgical intervention should be avoided in elderly patients who have little chance of survival. Octogenarians often have concomitant disease, such as renal insufficiency, chronic obstructive pulmonary disease, peripheral vascular disease, or degenerative cerebral disease. ${ }^{4}$ Therefore, they may not be able to tolerate the aggressive surgical stress of DHCA, a long duration of cerebral exclusion, or CPB. Furthermore, prolonged surgery can increase mortality through coagulopathy, cerebral ischemia, infection, or multiple organ failure. ${ }^{4,5}$ Therefore, particularly for octogenarians, performing surgery with the minimum invasive stress is considered to be a key factor for saving lives and maintaining quality of life.

TABLE 3. Durations for procedures

\begin{tabular}{lccc}
\hline & Group I & Group II & P value \\
\hline Core temperature $\left({ }^{\circ} \mathrm{C}\right)$ & $19.7 \pm 0.9$ & $27.5 \pm 0.5$ & $<.0001$ \\
Brain exclusion $(\mathrm{min})$ & $75.8 \pm 17.9$ & $18.8 \pm 6.2$ & $<.0001$ \\
CPB (min) & $201.2 \pm 44.1$ & $84.3 \pm 14.3$ & $<.0001$ \\
Operating time (min) & $425.6 \pm 79.5$ & $148.6 \pm 20.2$ & $<.0001$ \\
Postop hospital stay (d) & $33.7 \pm 12.2$ & $13.2 \pm 3.9$ & $<.0001$ \\
\hline
\end{tabular}

$C P B$, Cardiopulmonary bypass. 
TABLE 4. Complications

\begin{tabular}{lccc}
\hline & Group I & Group II & $\boldsymbol{P}$ value \\
\hline TND & $5(20 \%)$ & 0 & .0446 \\
Permanent brain damage & $5(20 \%)$ & 0 & .0446 \\
Re-exploration & $5(20 \%)$ & 0 & .0446 \\
ARF & $6(24 \%)$ & 0 & .0129 \\
Pneumonia & $7(28 \%)$ & $1(5.9 \%)$ & .0132 \\
Tracheostomy & $3(12 \%)$ & 0 & NS \\
Mortality & $6(24 \%)$ & 0 & .0291 \\
\hline
\end{tabular}

$T N D$, Temporal neurologic dysfunction; $A R F$, acute renal failure; NS, not significant.

Recently, the duration of brain exclusion, $\mathrm{CPB}$, and total operation for AAD has been reported to be approximately 60,200 , and 400 minutes, respectively. ${ }^{6-8}$ They all require DHCA and additional ACP. However, these durations are unnecessarily long. In the present study, in the patients of group I (DHCA), circulatory arrest also took about $75 \mathrm{~min}$ utes. This was because the three arch vessels were mobilized after initiation of DHCA. Then, balloon catheters for ACP were inserted into each vessel. Furthermore, we had waited approximately 10 minutes after GRF gluing. Also, the surgeon might take the procedure more slowly and gently because brain protection with ACP allows a more deliberate operation. Even though the open distal anastomosis was completed within 20 minutes in the hypothermic group, we had to take a long time for rewarming. Therefore, the duration of $\mathrm{CPB}$ was prolonged and the risk of coagulopathy was increased, particularly in octogenarians.

Kamiya and colleagues ${ }^{9}$ reported their quick proximal arch replacement, in which distal anastomosis was performed with moderate hypothermia $\left(26^{\circ} \mathrm{C}-28^{\circ} \mathrm{C}\right)$ without any cerebral perfusion. They described that the distal anastomosis could be completed in approximately 8 minutes. This was because almost all of their cases were elective surgery for true aneurysm, in which aortic stump fixation with GRF glue or Teflon felt is not required. However, the durations of CPB and overall operation for their procedures were about 130 and 240 minutes, respectively, ${ }^{9}$ which were much longer than those of our LIQR. In LIQR also, moderate hypothermic $\left(28^{\circ} \mathrm{C}\right)$ circulatory arrest without any cerebral perfusion for the distal anastomosis was performed. Although it took approximately 18 minutes to complete the distal anastomosis because of the need for aortic stump fixation with GRF glue and Teflon felt, the durations for CPB and overall operation were about 80 and 140 minutes, respectively, which were much quicker than those of previous reports. Our shortest operation time was 118 minutes from skin to skin. In general, quicker is not always better. However, particularly for octogenarians, we believe that quicker surgery definitely provides a better outcome because it can minimize the surgical stress resulting from hypothermia or CPB for weak octogenarians.
In the present study, all patients underwent femoral cannulation because it was considered much quicker and safer. In this series, no patient had malperfusion by femoral access. However, the procedure should be switched to antegrade blood perfusion with the side arm to ensure blood perfusion in the true lumen after excision of an intimal tear. In all patients, therefore, we used the side arm for blood perfusion after the open distal anastomosis.

In the present study, no cerebral complications were detected in any of the patients undergoing LIQR. On the other hand, 5 patients had brain injury during DHCA with ACP. This might be associated with too much stress for the octogenarian owing to DHCA. Cook and colleagues ${ }^{10}$ reported that systemic temperatures below $22^{\circ} \mathrm{C}$ may not be necessary and may be associated with a higher incidence of neurologic injury when using ACP during DHCA. Greeley and colleagues ${ }^{11}$ reported that patients cooled to $28^{\circ} \mathrm{C}$ had a predicted brain ischemic tolerance of 11 to 19 minutes. Our results suggest that moderate hypothermic arrest at $28^{\circ} \mathrm{C}$ without any adjunctive cerebral protection within 20 minutes is safe for octogenarians.

Another trick of this procedure is quick rewarming. It has been generally accepted that rewarming from hypothermia should be conducted as slowly as possible. ${ }^{12}$ In DHCA, cerebral metabolism and oxygen extraction remain significantly reduced during rewarming and after $\mathrm{CPB}$, suggesting disordered cerebral metabolism and oxygen use after DHCA. Furthermore, cerebral blood flow significantly decreases in patients with DHCA during the rewarming phase. ${ }^{13}$ If the cerebral circulation were unable to regulate oxygen delivery after DHCA, the brain would be at increased risk of hypoxic injury during episodes of hypoxemia in the rewarming phase. ${ }^{14}$ Therefore, we speculate that the potential mismatches in flow/metabolism after DHCA are most likely expressed during rapid temperature or perfusion changes such as during rewarming. On the other hand, Greeley and colleagues ${ }^{11}$ reported that patients cooled to $28^{\circ} \mathrm{C}$ demonstrated a return to baseline in cerebral blood flow during rewarming and after weaning from CPB. However, in patients exposed to DHCA, cerebral reperfusion was significantly lower during rewarming and after CPB. Therefore, we believe there is no problem with inducing rapid rewarming after circulatory arrest with moderate hypothermia $\left(28^{\circ} \mathrm{C}\right)$. Moreover, it can shorten the durations of CPB and the overall operation.

In the present study, there was no incidence of brain injury, re-exploration for bleeding, renal failure, respiratory failure, or hospital death among the patients who underwent LIQR. LIQR enabled us to rewarm the patients very quickly and shorten the CPB and operative duration. Finally, it helped to prevent severe complications in octogenarians. Actually, the 17 octogenarians treated with LIQR not only survived, but are also visiting outpatient clinic by themselves without any negative events to date. 


\section{Study Limitation}

This study has several limitations. It is a retrospective analysis of a single institution. Therefore, the sample size may be slightly small. Also, our LIQR is only acceptable for replacement of the proximal hemiarch. Fortunately, no patient in the LIQR group required total arch replacement. When we observe a long intimal tear on the midportion of the aortic arch during DHCA, we have to clamp the proximal arch again, cool the patient to about $24^{\circ} \mathrm{C}$ to $25^{\circ} \mathrm{C}$, and complete the arch replacement with concomitant use of ACP. In the present study, however, the subject was octogenarians. So far as we know, the data from our newly modified surgical technique for 17 consecutive octogenarians with AAD are unique. We have to keep monitoring the patients.

\section{Conclusion}

LIQR enables us to rewarm patients very quickly and shorten the CPB and operative durations. It should be a standard surgical technique for octogenarians with AAD.

\section{References}

1. Hata M, Sezai A, Niino T, Yoda M, Unosawa S, Minami K, et al. Should emergency surgical intervention be performed for octogenarian with type A acute aortic dissection? J Thorac Cardiovasc Surg. 2008;135: 1042-6.

2. Bachet J, Goudot B, Dreyfus GD, Brodaty D, Dubois C, Delentdecker P, et al. Surgery for acute type A aortic dissection: the Hopital Foch experience (1977-1998). Ann Thorac Surg. 1999;67:2006-9.

3. Ehrlich M, Fang WC, Grabenwöger M, Cartes-Zumelzu F, Wolner E, Havel M. Perioperative risk factors for mortality in patients with acute type A aortic dissection. Circulation. 1998;98(Suppl II): II294-8.

4. Chiappini B, Camurri N, Loforte A, Marco LD, Bartolomeo RD, Marinelli G. Outcome after aortic valve replacement in octogenarians. Ann Thorac Surg. 2004;78:85-9.

5. Westaby S, Saito S, Katsumata T. Acute type A dissection: conservative methods provide consistently low mortality. Ann Thorac Surg. 2002;73: 707-13.

6. Sato Y, Satokawa H, Takase S, Misawa Y, Wakamatsu H, Sato Y, et al. Therapeutic strategy for acute type A aortic dissection. Kyobugeka. 2007;60:262-6

7. Yoshimoto K, Oba J, Iijima M, Miyatake T, Eya K, Aoki H. Surgical treatment for acute type A aortic dissection. Kyobugeka. 2007;60: 267-72.

8. Kaneda K, Nishiwaki N, Nagato H, Hirao S, Heima D, Morishima A. Surgical treatment for type A acute aortic dissection; for better postoperative quality of life. Kyobugeka. 2007;60:273-8.

9. Kamiya H, Hagl C, Kropivnitskaya I, Weidermann J, Kallenbach K, Haverich A, et al. Quick proximal arch replacement with moderate hypothermic circulatory arrest. Ann Thorac Surg. 2007;83:1055-8.

10. Cook RC, Gao M, Macnab AJ, Fedoruk LM, Day N, Janusz MT. Aortic arch reconstruction: safety of moderate hypothermia and antegrade cerebral perfusion during systemic circulatory arrest. J Cardiovasc Surg. 2006;21:158-64.

11. Greeley WJ, Kern FH, Ungerleider RM, Boyd JL 3rd, Quill T, Smith LR, et al. The effect of hypothermic cardiopulmonary bypass and total circulatory arrest on cerebral metabolism in neonates, infants, and children. J Thorac Cardiovasc Surg. 1991;101:783-94.

12. Rosner MJ, Rosner SD, Johnson AH. Cerebral perfusion pressure: management protocol and clinical results. J Neurosurg. 1995;83: 949-62.

13. Croughwell ND, Frasco P, Blumenthal JA, Leone BJ, White WD, Reves JG. Warming during cardiopulmonary bypass is associated with jugular bulb desaturation. Ann Thorac Surg. 1992;53:827-32.

14. Tsui SSL, Schultz JM, Shen I, Ungerleider RM. Postoperative hypoxemia exacerbates potential brain injury after deep hypothermic circulatory arrest. Ann Thorac Surg. 2003;78:188-96. 